Article

\title{
An Efficient Polymer Inclusion Membrane-Based Device for Cd Monitoring in Seawater
}

\author{
Ibrahim Ait Khaldoun ${ }^{1,2}$, Lynda Mitiche ${ }^{2}$, Amar Sahmoune ${ }^{2}$ and Clàudia Fontàs ${ }^{1, *(1)}$ \\ 1 Department of Chemistry, University of Girona, C/Maria Aurèlia Capmany 69, 17003 Girona, Spain; \\ iaitkhaldoun@yahoo.fr \\ 2 Equipe de Recherche Matériaux et Procédés pour l'Environnement, Université Mouloud Mammeri \\ Tizi-Ouzou, Tizi-Ouzou 15000, Algeria; lynda76dz@yahoo.fr (L.M.); asahmoune@yahoo.fr (A.S.) \\ * Correspondence: claudia.fontas@udg.edu; Tel.: +34-648-426-341; Fax: +34-972-418-150
}

Received: 20 June 2018; Accepted: 6 August 2018; Published: 10 August 2018

\begin{abstract}
A novel and simple device that includes a polymer inclusion membrane (PIM) has been prepared and tested for the first time to detect low concentration levels of cadmium in seawater. The ionic liquid trihexyl (tetradecyl) phosphonium chloride (THTDPCl) has been shown to be an effective extractant when incorporated in a PIM that uses cellulose triacetate (CTA) as a polymer. However, it has been reported that the use of a plasticizer is mandatory to ensure an effective transport, which uses both ultrapure water and a nitric acid solution as a stripping phase. A special device incorporating a PIM made of 50\% CTA, 40\% nitrophenyl octyl ether (as a plasticizer), and 10\% THTDPCl, effectively allows the quantitative transport and preconcentration of $10 \mu \mathrm{g} \mathrm{L}^{-1} \mathrm{Cd}$ from seawater samples to a stripping phase consisting of $0.5 \mathrm{M} \mathrm{HNO}_{3}$ solution. This study shows that the efficiency of the PIM system is not affected by high salinity nor the presence of large amounts of other ions, and can thus facilitate $\mathrm{Cd}$ monitoring in seawater samples.
\end{abstract}

Keywords: cadmium; polymer inclusion membrane; trihexyl (tetradecyl) phosphonium chloride (THTDPCl); seawater

\section{Introduction}

The release of different pollutants into the environment, which has increased noticeably as a result of industrialization, is having an alarming effect on its quality. Heavy metals are the most important of these pollutants due to their non-biodegradability. In the case of cadmium, it is toxic even at trace concentrations. However, what is of most concern about this metal is its capacity for bioaccumulation. $\mathrm{Cd}$ in water is due nearly exclusively to industrial discharges (e.g., from electroplating, paint-making, the manufacture of plastics, etc.) and landfill leachates. High metal accumulation by organisms, and their consumption in the food chain, is a cause of major health problems and it is known that the marine food chain is seriously affected by $\mathrm{Cd}$ in seawater [1]. As a result, the accurate determination of this metal in seawater systems is receiving significant attention.

The presence of trace amounts of heavy metals in environmental samples is usually determined by either electrochemical or spectrophotometric techniques. However, the direct analysis of metals in seawater presents some difficulties due to the high salt content and low metal concentration, which results in matrix interference and insufficient precision, and so sample preparation is normally necessary prior to analysis. A possible solution to isolate $\mathrm{Cd}$ from seawater samples is to use an extractant diluted in an organic solvent. Taking advantage of the fact that $\mathrm{Cd}$ is mainly present as an anionic chlorocomplex in seawater, typical extractants used for its extraction in this media are anion exchangers, such as the quaternary ammonium salt Aliquat 336, which is an ionic liquid (IL) at room temperature. This IL, dissolved in kerosene with $0.25 \mathrm{M}$ dodecan-1-ol, formed a liquid membrane 
which was used to impregnate the pores of a fiber to act as a three phase solvent bar micro-extraction system [2]. The impregnated fiber was effective to preconcentrate $\mathrm{Cd}$ from seawater samples into a $1.5 \mathrm{M} \mathrm{HNO}_{3}$ solution (used as a stripping phase). More recently, a supported liquid membrane (SLM) containing this IL was developed and studied in both flat-sheet and hollow fiber configurations to separate $\mathrm{Cd}$ from complex aqueous samples [3]. It was found that using a $2 \mathrm{M} \mathrm{HCl}$ solution containing $\mathrm{Cd}, \mathrm{Cu}, \mathrm{Ni}$, and $\mathrm{Pb}$ as a feed phase, only $\mathrm{Cd}$ was transported. Additionally, $\mathrm{Cd}$ could be preconcentrated from spiked seawater samples using the SLM in hollow fiber configurations. Further, other IL based on phosphonium derivatives have also been proved to be effective extractants for Cd in chloride media. Singh et al. used Cyphos IL 102, diluted in toluene (trihexyl (tetradecyl) phosphonium bromid), to extract $\mathrm{Cd}$ and $\mathrm{Zn}$ from a hydrochloric acid medium [4]. Cyphos IL 104 (trihexyl (tetradecyl) phosphonium bis (2,4,4-trimethylpentyl) phosphinate), incorporated in a polymeric matrix, was shown to effectively remove $\mathrm{Cd}$ (II) from both $\mathrm{NaCl}$ and $\mathrm{HCl}$ solutions into a $1 \mathrm{M} \mathrm{H}_{2} \mathrm{SO}_{4}$ solution, which acted as a receiving phase [5]. Cyphos IL 101 (trihexyl (tetradecyl) phosphonium chloride) was immobilized in a synthetic resin (Amberlite XAD-7) to prepare a solvent impregnated resin (SIR). This SIR effectively allowed $\mathrm{Cd}$ (II) sorption in $\mathrm{HCl}$ solutions, and the extraction was found to occur via an exchange mechanism involving the reaction between chloroanionic $\mathrm{Cd}$ species and the phosphonium cation $\left(\mathrm{R}_{3} \mathrm{R}^{\prime} \mathrm{P}^{+}\right)[6]$.

Polymer inclusion membranes (PIMs), which are advanced liquid extracting membranes, can also be used to entrap the extractants. These membranes form homogeneous and non-porous films that have shown to be more stable than SLMs. PIMs are composed of a base polymer, providing mechanical strength, an extractant, which is immobilized within the chains of the base polymer, and in some cases, a plasticizer, which provides elasticity to the membrane. PIMs are of great interest for analytical purposes since they are very versatile and can be used for sample separation, sample preconcentration, and passive sampling, among others [7]. The use of devices incorporating PIMs allow compounds to be easily preconcentrated by using smaller volumes of the receiving phase, in comparison to the source solution. A PIM-device, containing Aliquat 336 as the carrier, allowed for the detection of As in groundwater [8]. A similar PIM-device was designed for the monitoring of antibiotic [9] Zn [10] or ammonia [11] in natural waters. However, to the best of our knowledge, there is no previous work on the use of such a PIM-device for the preconcentration of metals from seawater samples. Taking the complexity of natural water into account, it is important to investigate whether the high salinity or the presence of large amounts of other ions can affect the performance of the PIM-device.

In this study, we have developed a PIM incorporating IL trihexyl (tetradecyl) phosphonium chloride (THTDPCl) for the transport of $\mathrm{Cd}$ ions in a high chloride medium and have presented the results obtained using a PIM-device for the preconcentration of $\mathrm{Cd}$ from seawater samples.

\section{Materials and Methods}

\subsection{Chemicals}

Aqueous solutions of $\mathrm{Cd}$ were prepared by the dilution of the corresponding stock solution (1000 $\mathrm{mgL}^{-1}$, Romil, Cambridge, UK) and by the addition of $\mathrm{NaCl}$ (Panreac, Barcelona, Spain) to reach the desired chloride concentration. Nitric acid (Fluka, Buchs, Switzerland) and EDTA (Panreac, Spain) were used to prepare the stripping solutions and consisted of $0.5 \mathrm{M} \mathrm{HNO}_{3}$ or $0.1 \mathrm{M}$ EDTA. All chemicals were of analytical reagent grade and the solutions were prepared with ultrapure water obtained by purification through a Milli-Q Plus system (Millipore Iberica SA, Madrid, Spain).

The extractant-trihexyl (tetradecyl) phosphonium chloride (THTDPCl)—was purchased from Aldrich (Germany). The polymer cellulose triacetate (CTA) and the plasticizers 2-nitrophenyl octyl ether (NPOE), 2-Fluorophenyl 2-nitrophenyl ether (FPNPOE), and dibutyl sebacate (DBS), were purchased from Fluka Chemie (Switzerland), while chloroform was from Panreac (Spain). All of these reagents were used as received. 
Spiked seawater was obtained after adding the appropriate amount of $\mathrm{Cd}$ stock solution to seawater collected from the Mediterranean, it had the following chemical characteristics, $\mathrm{pH} 8.2$, conductivity $62 \mathrm{mS}, 0.62 \mathrm{M} \mathrm{Cl}^{-}, 0.68 \mathrm{M} \mathrm{Na}^{+}, 4325 \mathrm{mg} \mathrm{L}^{-1} \mathrm{SO}_{4}{ }^{2-}, 1415 \mathrm{mg} \mathrm{L}{ }^{-1} \mathrm{Mg}^{2+}, \mathrm{Ca}^{2+}, \mathrm{K}^{+}$, $\mathrm{HCO}_{3}{ }^{-}$, and the concentration was $<1000 \mathrm{mg} \mathrm{L}^{-1}$.

\subsection{Polymer Inclusion Membranes Preparation and Stability Test}

PIMs were prepared by following the procedure described by Garcia-Rodríguez [12]. The CTA amount was fixed at $200 \mathrm{mg}$ and other components were added to achieve the desired concentration of plasticizer and carrier. The composition of the PIMs (quoted in mass percentage) tested in this study, as well as the plasticizers characteristics, can be seen in Table 1.

The stability of PIM 2 was investigated in terms of mass loss, which is related to the loss of the carrier [13]. For that, PIM pieces of approximately $2 \mathrm{~cm} \times 2 \mathrm{~cm}$ were dipped in $25 \mathrm{~mL}$ of ultrapure water and were agitated in an orbital mixer for $24 \mathrm{~h}$. Membranes were weighed before and after this procedure, and the mass loss was calculated.

Table 1. Effect of PIM (polymer inclusion membrane) composition on Cd transport efficiency (24 h) and the characteristics of the plasticizers used to prepare the membranes. Feed phase: $10 \mathrm{mg} \mathrm{L}^{-1}$. Stripping phase: ultra-pure water.

\begin{tabular}{ccccccc}
\hline \multirow{2}{*}{ PIM } & \multirow{2}{*}{$\begin{array}{c}\text { Polymer } \\
\text { (CTA) (\%) }\end{array}$} & \multirow{2}{*}{$\begin{array}{c}\text { Carrier } \\
\text { (THTDPCl) (\%) }\end{array}$} & Content (\%) & Viscosity (cP) & Dielectric Constant $(\varepsilon)$ & TE $(\%)$ \\
\hline 1 & 70 & 30 & 0 & - & 0 \\
2 & & 30 & NPOE (20) & 12.8 & 23.1 & 50 \\
3 & 50 & 30 & FPNPOE (20) & 13 & 71.8 \\
4 & & 30 & DBS $(20)$ & 9.5 & 4.5 & 84.1 \\
\hline
\end{tabular}

\subsection{Instrumentation}

$\mathrm{Cd}$ determination in the feed and stripping phases was made by atomic emission spectrometry with an ICP-AES instrument (Varian Liberty RL, Victoria, Australia), and a KS250 multiple stirrer (Ika, Labortechnik, Staufen, Germany) was used for transport experiments.

The scanning electron microscopy (SEM) observations of the membrane samples were made using a FE-SEM Hitachi S-4100 (Tokyo, Japan). The samples were placed on a stub and coated with carbon (model K950 turbo evaporator, Emitech, Lohmar, Germany). Digital images were collected and processed by Quarz PCI program (Vancouver, BC, Canada).

\subsection{Transport and Preconcentration Experiments}

To evaluate the use of PIMs for the transport of $\mathrm{Cd}$, some experiments were performed in a two compartment membrane cell, described elsewhere [14], with $190 \mathrm{~mL}$ of both feed solution $\left(10 \mathrm{mg} \mathrm{L}^{-1} \mathrm{Cd}\right.$ in $\left.2 \mathrm{M} \mathrm{NaCl}\right)$ and a stripping phase was used that incorporated a PIM of $11 \mathrm{~cm}^{2}$ in area. Preconcentration studies were done using a device containing a PIM of $2.5 \mathrm{~cm}^{2}$ in contact with $100 \mathrm{~mL}$ of feed solution in agitation. In order to allow for preconcentration, only $5 \mathrm{~mL}$ of a stagnant stripping solution was used. A scheme of the PIM-device and the whole setup can be found in [15]. Samples were withdrawn and analysed by ICP-AES. The percentage of Cd extraction, $E(\%)$, was then calculated by Equation (1):

$$
E(\%)=\frac{[C d]_{f_{e e d}(0)}-[C d]_{\text {feed }_{(t)}}}{[C d]_{f e e d_{(0)}}} \times 100
$$

where $[C d]_{f e e d(0)}$ is the initial $C d$ concentration in the water sample, whereas $[C d]_{f e e d(t)}$ is the metal concentration in the source solution at the end of the experiment $(24 \mathrm{~h})$. Cd transport efficiency (TE) was determined using Equation (2): 


$$
T E(\%)=\frac{[C d]_{\text {strip }_{(t)}}}{[C d]_{\text {feed }_{(0)}}} \frac{1}{V r} \times 100
$$

where $[C d]_{\text {strip }(t)}$ denotes the metal concentration in the stripping compartment at the end of the contact time. The volume ratio between feed solution and stripping solutions is denoted by $V r$. For the two-compartment cell $V r=1$, and for the PIM device $V r=20$.

\section{Results}

\subsection{Characteristics of the Polymer Inclusion Membranes (PIMs)}

All the PIMs investigated in this study were effectively prepared indistinctly when they only contained CTA and the extractant THTDPCl or when they incorporated the added plasticizers NPOE, FNPOE, and DBS. The addition of a plasticizer reduces the glass transition temperature of the polymer and can also facilitate the transport of the target species through the PIM [16]. All the membranes were transparent, homogeneous, and mechanically stable. Figure 1 shows the morphology of the PIM containing NPOE as a plasticizer (M2), and it can be seen that the resulting membrane was dense and without pores.
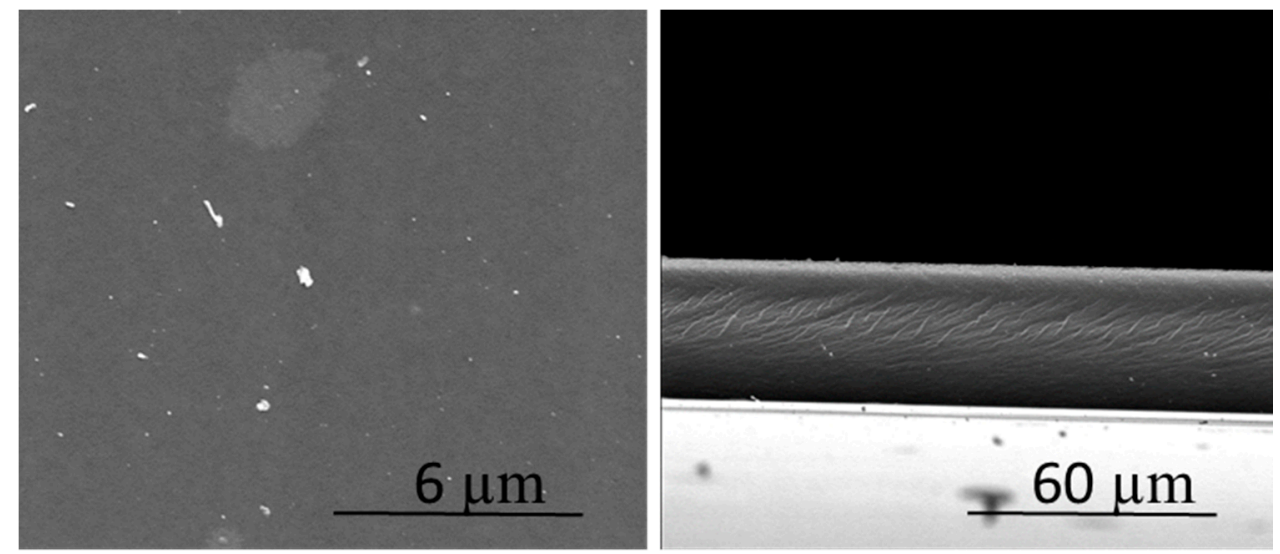

Figure 1. SEM images of a PIM with a composition of 50\% CTA, 30\% THTDPCl, and 20\% NPOE. (Left) surface; (right) cross-section.

The stability of the membrane M2 was investigated in terms of the extent of leaching of the IL from the membrane in aqueous solutions. Membrane mass loss was found to be $9 \pm 1 \%(n=3)$. This value is much lower than the obtained value for a PIM made of polyvinyl chloride (PVC), and the similar content of Aliquat 336, which was reported to be 33\% [17].

\subsection{Transport Experiments}

All the produced membranes (M1-M4) were used in the investigation of the transport of Cd from a $2 \mathrm{M} \mathrm{NaCl}$ solution to an ultra-pure water-stripping phase. Transport efficiency, shown in Table 1, was calculated after $24 \mathrm{~h}$ using Equation (2). As can be seen, PIM 1, which did not contain any plasticizer, was not able to transport Cd. However, from Figure 2a, where the transient concentration curves are presented for this PIM, it is observed that even though the extraction of the metal occurred (depletion of the feed phase), it was not transported to the stripping phase. In comparison, in the case of PIM 2 (see Figure $2 b$ ), the metal extracted in the feed phase was released in the stripping compartment, reaching a transport efficiency of $82.2 \%$. This good performance was observed for all the PIMs containing a plasticizer-independently of their nature (NPOE and FNPOE are aromatic compounds while DBS is aliphatic) and their characteristics (high or low dielectric constant, for example). The need 
to add a plasticizer to enable the transport of Cd in a PIM was also observed using Aliquat 336 as the carrier [18].

The transport process can be described by the reaction between the metal and the carrier $\left(\mathrm{R}_{4} \mathrm{P}^{+} \mathrm{Cl}^{-}\right)$ present in the PIM:

$$
n \mathrm{R}_{4} \mathrm{P}^{+} \mathrm{Cl}^{-}{ }_{\mathrm{PIM}}+\left[\mathrm{CdCl}_{n+2}\right]^{\mathrm{n}-}{ }_{(\mathrm{aq})} \rightarrow\left[\left(\mathrm{PR}_{4}\right)_{n} \mathrm{CdCl}_{n+2}\right] \mathrm{PIM}+n \mathrm{Cl}^{-}{ }_{(\mathrm{aq})}
$$

where $\mathrm{n}$ can be one or two, and the subscripts aq and PIM denote the aqueous and membrane phases, respectively. It is worth mentioning that when Aliquat 336 is used as the extractant, it has been reported that $\mathrm{CdCl}_{4}{ }^{2-}$ species are responsible for the extraction in non-viscous media [3], whereas $\mathrm{CdCl}_{3}{ }^{-}$ species are responsible for the extraction when viscous diluents are used [18].
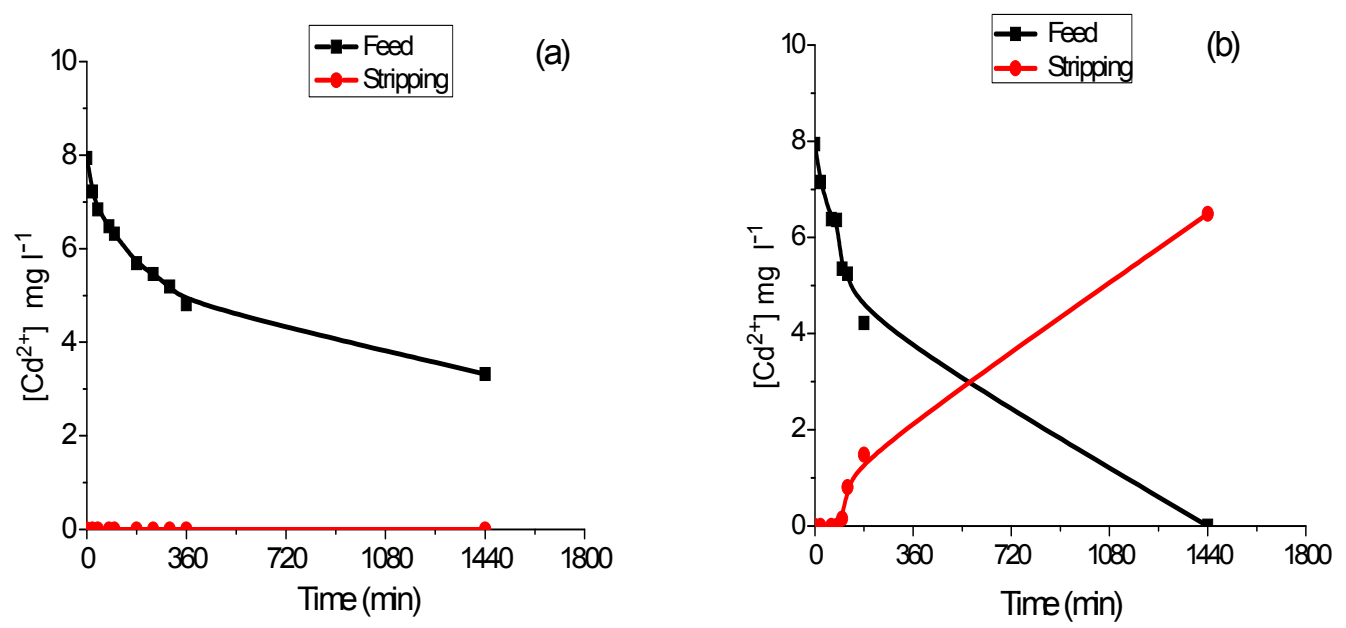

Figure 2. Transient concentration curves in Cd (II) transport experiments involving PIM 1 (a) and PIM 2 (b).

The stripping step is understood to be the release of $\mathrm{Cd}$ in ultra-pure water due to the fact that the predominant species of the metal in this medium $\left(\mathrm{Cd}^{2+}\right)$ cannot interact with the carrier. Moreover, other stripping solutions were tested using PIM 2, such as a $0.5 \mathrm{M} \mathrm{HNO}_{3}$ or a $0.1 \mathrm{M}$ EDTA solution. It was found that the transport of $\mathrm{Cd}$ using nitric acid followed the same trend as ultra-pure water. In this case, stripping is due to both the predominance of $\mathrm{Cd}^{2+}$ and the interaction of the nitrate anion with $\left(\mathrm{R}_{4} \mathrm{P}\right)^{+}$, which forms the $\left(\mathrm{R}_{4} \mathrm{P}\right)^{+} \mathrm{NO}_{3}{ }^{-}$ion pair [19]. However, EDTA solution only allowed for the recovery of about $20 \%$ of the metal and thus this reagent was discarded in further experiments.

\subsection{Cadmium Preconcentration Using the PIM-Device}

Based on the transport results, it was decided that a PIM 2 was to be used in the device and to investigate its capacity for the preconcentration of very low $\mathrm{Cd}$ content solutions in $0.5 \mathrm{M} \mathrm{NaCl}$ (to resemble a seawater sample), which also tested nitric acid and ultra-pure water as stripping solutions. The results, presented in Figure 3, show that in both cases it was necessary to lengthen the experiment to $24 \mathrm{~h}$ to obtain quantitative extraction and a $0.5 \mathrm{M} \mathrm{HNO}_{3}$ allowed the highest transport value. However, it should be noted that in this more favorable case, $37 \%$ of the initial metal remained in the PIM. The fact that the extracted metal is not completely released in the stripping phase, as occurred when using the two-compartment transport cell, may be due to the lack of agitation in this latter phase. 


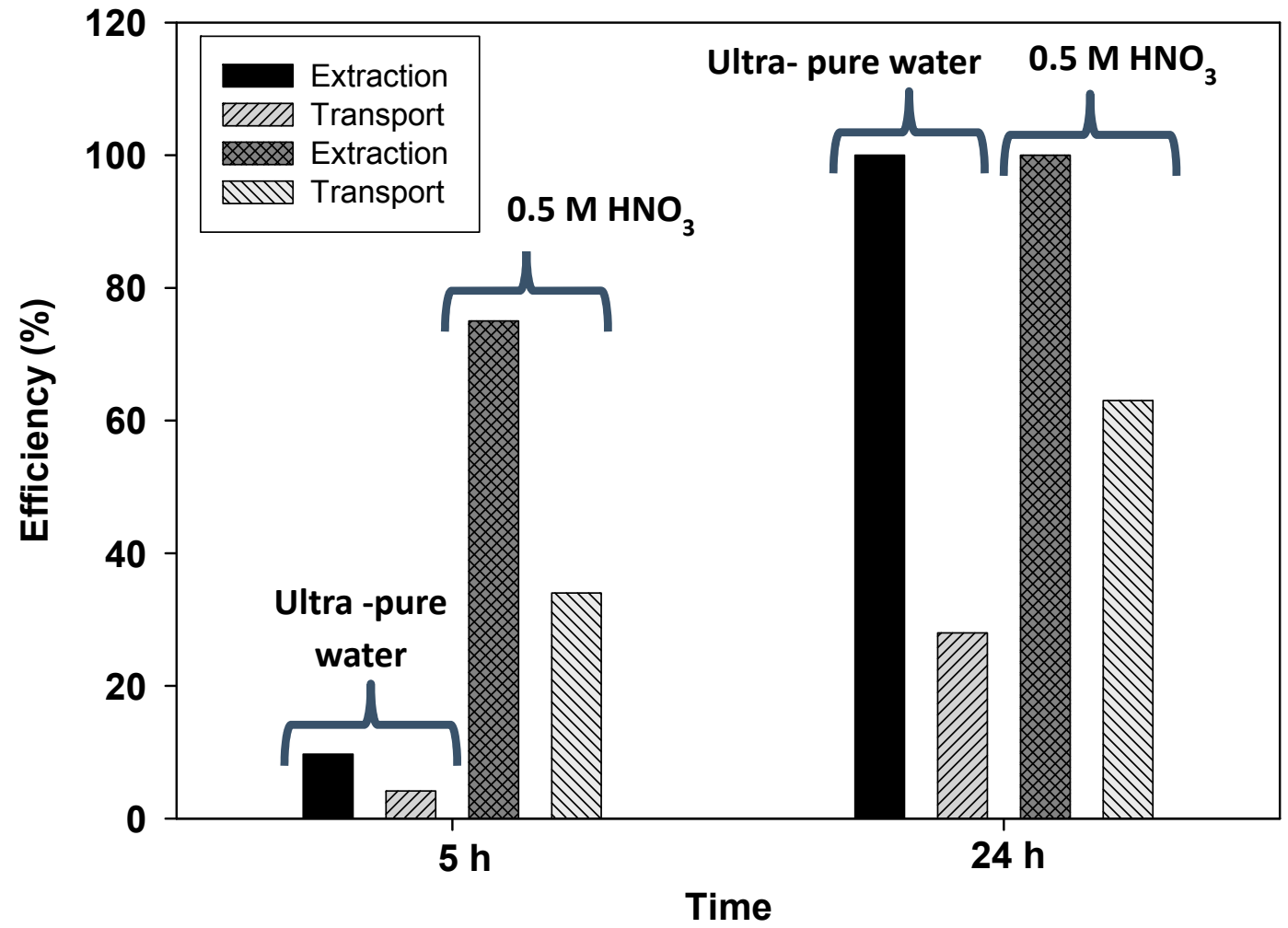

Figure 3. Effect of the stripping phase composition on Cd extraction and recovery vs. time. Feed phase: $0.5 \mathrm{mg} \mathrm{L}^{-1} \mathrm{Cd}$ in $0.5 \mathrm{M} \mathrm{NaCl}$. PIM 2.

Given this, in order to enhance transport and release in the stripping phase, we tested the composition of other membranes with a higher amount of plasticizer, $40 \%$ instead of $20 \%$ (for both NPOE and DBS), while maintaining the same amount of CTA (50\%) with the aim of decreasing the viscosity of the PIM. By means of these new PIMs, and using a $0.5 \mathrm{M} \mathrm{HNO}_{3}$ as the stripping phase, it was found that all the $\mathrm{Cd}$ extracted in the feed phase was quantitatively transported to the stripping compartment after $24 \mathrm{~h}$ for the PIM with NPOE, while the PIM with DBS transported $93 \%$ of the initial metal. Thus, membranes with only $10 \%$ of the carrier in addition to a lower viscosity, allowed for both effective extraction and transport, which solved the problem that the lack of agitation of the small volume of stripping phase posed. Finally, a PIM consisting of 50\% CTA $+10 \%$ THTDPCl + $40 \% \mathrm{NPOE}$, incorporated in the device, was used for the preconcentration of $10 \mu \mathrm{g} \mathrm{L}^{-1}$ of Cd in both $0.5 \mathrm{M} \mathrm{NaCl}$ and spiked seawater samples. The results are presented in Table 2 where it can be seen that the developed preconcentration method allows for the total recovery of the metal in the stripping phase. The fact that the values are similar in both solutions shows that $\mathrm{Cd}$ transport is not affected by other ions present in seawater. Moreover, since the metal is preconcentrated and released in a clean matrix (nitric acid), it facilitates its determination by spectrophotometric techniques, which are not suitable for the direct measurement of the metal in high saline solutions.

Table 2. Cd preconcentration using the PIM-device (24 h). PIM: $50 \%$ CTA + 10\% THTDPCl + 40\% NPOE.

\begin{tabular}{cccc}
\hline Sample & Cd Stripping Phase $\left(\mu \mathbf{g ~ L}^{-\mathbf{1}}\right)$ & TE (\%) & Recovery (\%) \pm SD \\
\hline \multirow{2}{*}{$0.5 \mathrm{M} \mathrm{NaCl}+10 \mu \mathrm{g} \mathrm{L}^{-1} \mathrm{Cd}$} & 238.33 & 119 & $108 \pm 15$ \\
\hline \multirow{2}{*}{ Seawater $+10 \mu \mathrm{g} \mathrm{L}^{-1} \mathrm{Cd}$} & 194.30 & 98 & \multirow{2}{*}{$99 \pm 4$} \\
\hline
\end{tabular}




\section{Conclusions}

A successful transport of $\mathrm{Cd}$ from chloride solutions has been accomplished using a PIM consisting of CTA as the polymer, THTDPCl as the carrier, and DBS or NPOE as the plasticizer. Even though both ultrapure water and nitric acid solutions are suitable stripping solutions, when the PIM is used for preconcentration purposes, a $0.5 \mathrm{M} \mathrm{HNO}_{3}$ solution is more efficient. A membrane consisting of $50 \%$ CTA $+10 \%$ THTDPCl $+40 \%$ NPOE enabled Cd transport from seawater samples containing only $10 \mu \mathrm{g} \mathrm{L}^{-1}$, achieving in a single step both metal preconcentration and a matrix clean-up. These results show that the PIM system designed here is an efficient analytical tool that should be considered for Cd monitoring in complex natural waters.

Author Contributions: I.A.K. conducted the experimental work as a Ph.D. student under the supervision of C.F. and A.S. C.F., A.S. and L.M. contributed to the discussion of the results. C.F. was the responsible of writing the manuscript.

Funding: This research was funded by Ministerio de Economía y Competitividad grant number CTM2016-78798-C2-2-P (AEI/FEDER/UE).

Conflicts of Interest: The authors declare no conflict of interest.

\section{References}

1. Angeletti, R.; Binato, G.; Guidotti, M.; Morelli, S.; Pastorelli, A.A.; Sagratella, E.; Ciardullo, S.; Stacchini, P. Cadmium bioaccumulation in mediterranean spider crab (Maya squinado): Human consumption and health implications for exposure in italian population. Chemosphere 2014, 100, 83-88. [CrossRef] [PubMed]

2. Herce-Sesa, B.; López-López, J.A.; Moreno, C. Ionic liquid solvent bar micro-extraction of CdC $\ln _{(\mathrm{n}-2)}{ }^{-\mathrm{species}}$ for ultra-trace Cd determination in seawater. Chemosphere 2018, 193, 306-312. [CrossRef] [PubMed]

3. Pont, N.; Salvadó, V.; Fontàs, C. Applicability of a supported liquid membrane in the enrichment and determination of cadmium from complex aqueous samples. Membranes 2018, 8, 21. [CrossRef] [PubMed]

4. Singh, R.; Mahandra, H.; Gupta, B. Solvent extraction studies on cadmium and zinc using Cyphos IL 102 and recovery of zinc from zinc-plating mud. Hydrometallurgy 2017, 172, 11-18. [CrossRef]

5. Pospiech, B. Studies on extraction and permeation of cadmium(II) using Cyphos IL 104 as selective extractant and ion carrier. Hydrometallurgy 2015, 154, 88-94. [CrossRef]

6. Arias, A.; Saucedo, I.; Navarro, R.; Gallardo, V.; Martinez, M.; Guibal, E. Cadmium(II) recovery from hydrochloric acid solutions using Amberlite XAD-7 impregnated with a tetraalkyl phosphonium ionic liquid. React. Funct. Polym. 2011, 71, 1059-1070. [CrossRef]

7. Almeida, M.I.G.S.; Cattrall, R.W.; Kolev, S.D. Polymer inclusion membranes (PIMs) in chemical analysis-A review. Anal. Chim. Acta 2017, 987, 1-14. [CrossRef] [PubMed]

8. Fontàs, C.; Vera, R.; Batalla, A.; Kolev, S.D.; Anticó, E. A novel low-cost detection method for screening of arsenic in groundwater. Environ. Sci. Pollut. Res. 2014, 21, 11682-11688. [CrossRef] [PubMed]

9. Garcia-Rodríguez, A.; Fontàs, C.; Matamoros, V.; Almeida, M.I.G.S.; Cattrall, R.W.; Kolev, S.D. Development of a polymer inclusion membrane-based passive sampler for monitoring of sulfamethoxazole in natural waters. Minimizing the effect of the flow pattern of the aquatic system. Microchem. J. 2016, 124, 175-180. [CrossRef]

10. Almeida, M.I.G.S.; Chan, C.; Pettigrove, V.J.; Cattrall, R.W.; Kolev, S.D. Development of a passive sampler for Zinc(II) in urban pond waters using a polymer inclusion membrane. Environ. Pollut. 2014, 193, $233-239$. [CrossRef] [PubMed]

11. Almeida, M.I.G.S.; Silva, A.M.L.; Coleman, R.A.; Pettigrove, V.J.; Cattrall, R.W.; Kolev, S.D. Development of a passive sampler based on a polymer inclusion membrane for total ammonia monitoring in freshwaters. Anal. Bioanal. Chem. 2016, 408, 3213-3222. [CrossRef] [PubMed]

12. Garcia-Rodríguez, A.; Matamoros, V.; Kolev, S.D.; Fontàs, C. Development of a polymer inclusion membrane (PIM) for the preconcentration of antibiotics in environmental water samples. J. Membr. Sci. 2015, 492, 32-39. [CrossRef]

13. Kagaya, S.; Ryokan, Y.; Cattrall, R.W.; Kolev, S.D. Stability studies of poly(vinyl chloride)-based polymer inclusion membranes containing Aliquat 336 as a carrier. Sep. Purif. Technol. 2012, 101, 69-75. [CrossRef] 
14. Fontàs, C.; Salvadó, V.; Hidalgo, M. Selective enrichment of palladium from spent automotive catalysts by using a liquid membrane system. J. Membr. Sci. 2003, 223, 39-48. [CrossRef]

15. Vera, R.; Fontàs, C.; Galceran, J.; Serra, O.; Anticó, E. Polymer inclusion membrane to access Zn speciation: Comparison with root uptake. Sci. Total Environ. 2018, 622, 316-324. [CrossRef] [PubMed]

16. Fontàs, C.; Tayeb, R.; Dhahbi, M.; Gaudichet, E.; Thominette, F.; Roy, P.; Steenkeste, K.; Fontaine-Aupart, M.-P.; Tingry, S.; Tronel-Peyroz, E.; et al. Polymer inclusion membranes: The concept of fixed sites membrane revised. J. Membr. Sci. 2007, 290, 62-72. [CrossRef]

17. Argiropoulos, G.; Cattrall, R. The study of a membrane for extracting gold (III) from hydrochloric acid solutions. J. Membr. Sci. 1998, 138, 279-285. [CrossRef]

18. Pont, N.; Salvadó, V.; Fontàs, C. Selective transport and removal of Cd from chloride solutions by polymer inclusion membranes. J. Membr. Sci. 2008, 318, 340-345. [CrossRef]

19. Vera, R.; Gelde, L.; Anticó, E.; Martínez de Yuso, M.V.; Benavente, J.; Fontàs, C. Tuning physicochemical, electrochemical and transport characteristics of polymer inclusion membrane by varying the counter-anion of the ionic liquid Aliquat 336. J. Membr. Sci. 2017, 529, 87-94. [CrossRef]

(C) 2018 by the authors. Licensee MDPI, Basel, Switzerland. This article is an open access article distributed under the terms and conditions of the Creative Commons Attribution (CC BY) license (http://creativecommons.org/licenses/by/4.0/). 